\title{
Thermogravimetric analysis of empty fruit bunch
}

\author{
Girma T. Chala ${ }^{1 *}$, Ying P. $\operatorname{Lim}^{1 \dagger}$, Shaharin A. Sulaiman ${ }^{2}$, and Chin L. Liew ${ }^{1}$ \\ ${ }^{1}$ Department of Mechanical Engineering, INTI International University, Persiaran Perdana BBN, \\ 71800 Nilai, Negeri Sembilan, Malaysia \\ ${ }^{2}$ Department of Mechanical Engineering, Universiti Teknologi PETRONAS, Bandar Seri Iskandar \\ 32610 Tronoh, Perak, Malaysia
}

\begin{abstract}
This paper presents the characteristics of empty fruit bunch (EFB) using thermogravimetric analysis (TGA) and shows its potential as a renewable energy sources. A set of data were collected from the thermal reaction and plotted in mass or percentage of the initial mass against either temperature or time, respectively. In the thermogravimetric analysis, mass, temperature and time were considered as base measurements and important data for derivative thermogravimetric (DTG) curve were analysed while many additional measures could be derived from these three base measurements. It was observed that heating rate of $8.5^{\circ} \mathrm{C} / \mathrm{min}$ and air flow rate of $85 \mathrm{~mL} / \mathrm{min}$ provided a maximum weight loss rate of $0.209 \% /{ }^{\circ} \mathrm{C}$ at the temperature of $313.5^{\circ} \mathrm{C}$ and the derivative weight peak of $-0.1895 \mathrm{mg} /{ }^{\circ} \mathrm{C}$ at $292^{\circ} \mathrm{C}$. The time taken to reach the maximum temperature of $899.9^{\circ} \mathrm{C}$ was 46.74 minutes, and $\Delta \mathrm{T}$ endo-up reflected minimum point of $-0.2^{\circ} \mathrm{C}$ at 15.82 minutes and maximum $\Delta \mathrm{T}$ endo-up of $888^{\circ} \mathrm{C}$ at 42 minutes. Heat flow endo-up also showed that the minimum heat flow was $15.39 \mathrm{~mW}$ at 15.85 minutes and reaching the peak heat flow endo-up of $47.73 \mathrm{~mW}$ at 43.27 minutes.
\end{abstract}

\section{Introduction}

Nowadays, the growth in the energy demand worldwide and severe environmental condition pushed to consider renewable energy sources such as solar, wind, wave and tidal, geothermal, hydro, biomass energies as an alternative energy sources [1]. Particularly, renewable resources are providing significant energy for the countries under rapid economic development. With such advantage of using renewable energy, Malaysia government has turned the attention towards palm oil industrial in Malaysia. Malaysia has the capability of contributing lignocellulosic biomass in more than $90 \%$ in total with a massive delivering of $5.4 \mathrm{mil}$ ton hectare of oil palm [2]. For instance, in year 2005, palm oil industries were projected to produce approximately 15 million tonnes (301,000 barrels per day) [3]. In recent years, huge replanting activity, expanding mill capacity and improvement on palm oil exchange rate have given the opportunity to utilize oil palm as renewable energy sources. On the other hand, after the massive production of oil palm, the solid wastes such as empty fruit brunch (EFB), mesocarp (MF), and palm kernel shell (PKS) were left over and can be reused

\footnotetext{
${ }^{*}$ Corresponding author: girma tade@yahoo.com

${ }^{\dagger}$ Corresponding author: limyingpio@gmail.com
} 
as energy sources. EFB is a by-product of Fresh Fruit Bunch (FFB) following the removal of the nut, which could be used to produce useful fuels. The presence of high amount of fixed carbon makes EFB to be a potential renewable energy sources.

Fully utilizing the EFB's lignocellulose would be an alternative solution as renewable energy. In rough estimation, palm oil would obtain approximately $4 \mathrm{~kg}$ of lignocellulosic biomass including EFB's cellulose, hemicellulose and lignin $[4,5]$. The cellulose's content in EFB's palm oil is in the range of $37.3 \%$ - $46.5 \%$ whereas hemicellulose content is $25.3 \%$ $33.8 \%$ and lignin of $27.6 \%-32.5 \%$, respectively [6]. As a result, EFB was found to be potential for fermentation production of bioethanol due to its high cellulose content. This energy is usually obtained via thermochemical treatments, such as pyrolysis, gasification, and combustion [3]. Through thermochemical treatment, EFB could be used to produce ethanol as pre-treatment was required to render the cellulose fibre more amenable to the action of hydrolytic enzymes.

Oil palm has the highest yielding oil crop compared to other crops such as soybean, sunflower, rapeseed with the advantage of 10:1 ratio [6]. From the high yielding of oil palm, a fermentation process could be deployed to generate bio-ethanol from sugar or starch. From the palm tree, empty fruit bunch (EFB) has the highest sugar content compared to other parts and is suitable to produce bio-ethanol through pyrolysis and fermentation or hydrolysis. The percentage of both ultimate and proximate analyses were used to indicate the energy content within EFB itself and upon combustion with the required amount of air as well as other composition of gases released during the combustion through traditional method of water retting process [7]. In proximate analysis, EFB would consist $83.86 \%$ of volatile matter, $18.3 \%$ of fixed carbon and $13.65 \%$ ash with the moisture content of $14.28 \%$. Due to high volatile matter in EFB, the ignition towards EFB was possible at the temperature of $190^{\circ} \mathrm{C}$, whereas the fixed carbon determines the amount of heat and energy produced during the burning processes. It was found that ultimate analysis from EFB after combustion showed $2.4 \%$ potassium oxide and it is the highest percentage compared to magnesium oxide $(0.23 \%)$, silica $(0.19 \%)$, phosphorous pentoxide $(0.18 \%)$ and calcium oxide $(0.13 \%)$ [8].

The conversion of EFB into useful fuel could be done in either fast or slow pyrolysis or even through gasification. A quick pyrolysis, conducted at higher temperature $\left(>400{ }^{\circ} \mathrm{C}\right)$ and over a shorter home time $(<30 \mathrm{~s})$, is more ideal since it tends to give a higher liquid product yield [9]. Production of bio-oil from EFB could be performed by quick pyrolysis, either without or with a catalyst presence and it can be done in a fluidized-bed, fixed bed or auger type system. Beside pyrolysis, solvolysis, another sort of thermochemical process, has been utilized to convert EFB into bio-oil [8].

TGA could furnish a straightforward process and analysis method such as proximate analysis, heating value, and hemicellulose/cellulose/lignin ratio, which are the parameters of more noteworthy criticalness influencing kinetics energy [10]. Furthermore, deconvolution of Derivative Thermogravimetric (DTG) curve is proposed to calculate the substance of hemicellulose, cellulose and lignin and the utilization of non-linear regression techniques for the correlation substance of moisture, fixed carbon, volatile component and ashes consisting of carbon, hydrogen, oxygen, nitrogen, sulphur and higher heating value, HHV [3]. Moreover, TGA or DTG graphs help analyse the reaction of feedstock against the condition perimeter setup for the analysis. The objective of this paper was therefore to identify the characteristic of empty fruit bunch (EFB) and show its potential as renewable resources through Thermogravimetric Analysis. This would provide a better understanding of the behaviour of solid fuel during combustion, thermochemical and biochemical conversions.

\section{Materials and methods}


A test was carried out with the dry shredder EFB beforehand to avoid contamination for later non-isothermal experiment. In this experiment, a small amount of the EFB was placed in the alumina crucible and placed into a furnace for continuous heating under controlled temperature at the rate of $8.5^{\circ} \mathrm{C}$ per minute with the air flow rate of $85 \mathrm{~mL} / \mathrm{min}$. The reaction of the EFB inside the furnace was recorded automatically into the log system providing various selection of feedstock weight, temperature and time difference. The recorded data on the TGA and DTG provide the percentage of ultimate analysis, proximate analysis and chemical structure for the EFB. The extracted information from TGA and DTG would be valuable for later analysis on gasification of EFB.

\section{Results and discussion}

Fig. 1 shows TGA and DTG of EFB over temperature raging from $0^{\circ} \mathrm{C}$ to $899.9^{\circ} \mathrm{C}$. EFB underwent three main stages degradation: drying and evaporation of light components (phase one), devolatilization of cellulose and hemicellulose (phase two) and decomposition of lignin (phase three) [11]. The first phase of drying and evaporation of light components ranged from $97.85^{\circ} \mathrm{C}$ to $196.5^{\circ} \mathrm{C}$. The drying and evaporation of EFB caused the mass reduction from $99.3758 \%$ to $96.8547 \%$ with $2.5211 \%$ weight losses at a rate of $0.025 \% /{ }^{\circ} \mathrm{C}$. A significant drop of weight in the temperature range of $196.5^{\circ} \mathrm{C}$ to $510^{\circ} \mathrm{C}$ indicated phase two of devolatilization of cellulose and hemicellulose of EFB with wt $\%$ of EFB reduced from $96.85 \%$ to $31.206 \%$. In phase two, total weight losses were $65.648 \%$ in the total temperature increment of $313.5^{\circ} \mathrm{C}$ at a rate of $0.21 \% /{ }^{\circ} \mathrm{C}$. When temperature reached $510^{\circ} \mathrm{C}$, which is phase three, a slow and stable mass loss was observed as the degradation of lignin compounds and other strong chemical bond compounds were left over for long and high temperature degradation. The weight of EFB reduced from $31.2 \%$ to $11.05 \%$ at the end of the analysis. The rate of weight loss was $0.0516 \%$. It was also observed that a maximum temperature of $900^{\circ} \mathrm{C}$ was unable to complete combustion due to its $11.056 \%$ inorganic components [12].

As for DTG, phase one started with an intensive mass loss of $-0.061 \mathrm{mg} /{ }^{\circ} \mathrm{C}$ at $53{ }^{\circ} \mathrm{C}$ and this was followed up with a second derivative weight peak of -0.1895 at $292^{\circ} \mathrm{C}$. From DTG, EFB components underwent combustion within the temperature from $272^{\circ} \mathrm{C}$ to $314^{\circ} \mathrm{C}$. The remaining components underwent combustion within the range of $450^{\circ} \mathrm{C}$ and $510^{\circ} \mathrm{C}$. From the analysis, a minimum gasification temperature would be around $900^{\circ} \mathrm{C}$ to complete gasification process [13]. TGA and DTG also showed mass losses with an increase in temperature and heating rate in the furnace [14].

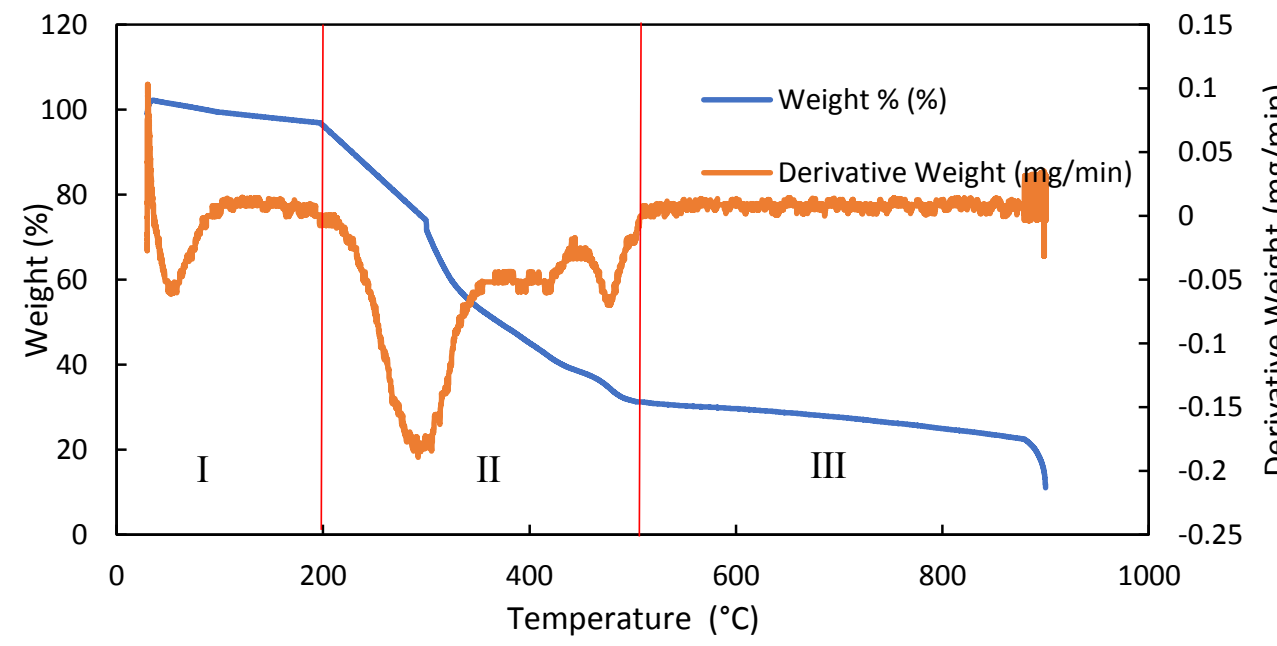


Fig. 1. TGA and DTG of EFB

\subsection{Others sample details of EFB}

To have a better understanding on EFB, other characteristics were taken into consideration. Fig. 2 shows the comparison between time against $\Delta \mathrm{T}$ endo-up and temperature. $\Delta \mathrm{T}$ endo-up indicates a difference between the maximum and minimum temperature during endothermic process. The initial temperature started at $29.71^{\circ} \mathrm{C}$ and $\Delta \mathrm{T}$ endo-up started at $0.065^{\circ} \mathrm{C}$. When the temperature increased $\Delta \mathrm{T}$ endo-up gradually increased before a significant drop at temperature of $325.7^{\circ} \mathrm{C}$ with $-0.2^{\circ} \mathrm{C}$ of $\Delta \mathrm{T}$ endo-up as the devolatilization occurred at $440^{\circ} \mathrm{C}$. Slowly the $\Delta \mathrm{T}$ endo-up increased back to $0.49^{\circ} \mathrm{C}$ at the temperature of $455.7^{\circ} \mathrm{C}$ and a second significate drop of $\Delta \mathrm{T}$ endo-up at the minimum point of $-0.16^{\circ} \mathrm{C}$ was at the temperature of $480.43^{\circ} \mathrm{C}$. The second drop of $\Delta \mathrm{T}$ endo-up was observed before the degradation of lignin compounds hitting the minimum value of $\Delta \mathrm{T}$. The delta temperature increased rapidly from $-0.16^{\circ} \mathrm{C}$ to $0.78^{\circ} \mathrm{C}$ at the temperature between $480.11^{\circ} \mathrm{C}$ and $511.27^{\circ} \mathrm{C}$. When the temperature reached $511.27^{\circ} \mathrm{C}$, the degradation of lignin occurred, causing the chemical composition of EFB reaction under high temperature degradation. At high temperature, the delta $T$ increased gradually from $0.78^{\circ} \mathrm{C}$ to $1.61^{\circ} \mathrm{C}$. The total time taken for the TGA was approximately 46.74 minutes. For drying and evaporation (phase 1), the heat flow endo-up reached the maximum point of $31.17 \mathrm{~mW}$ at 9.1 minutes. After the completion of drying and evaporation, the first fall of $\Delta \mathrm{T}$ was at $15.69 \mathrm{~min}$ with $-0.2^{\circ} \mathrm{C}$, indicating that the $\mathrm{EFB}$ was not absorbing the heat before the devolatilization of hemicellulose and cellulose of the EFB component. In the early stage of devolatilization, $\Delta \mathrm{T}$ increased and the maximum devolatilization of EFB occurred at 22 minutes with the maximum $\Delta \mathrm{T}$ of $0.49^{\circ} \mathrm{C}$. Right after the devolatilization (phase 2), $\Delta \mathrm{T}$ dropped rapidly and reached the minimum delta temperature of $-0.16^{\circ} \mathrm{C}$ in 1 minute. Chemical bonds took the longest time of 20 minutes to reach the maximum $\Delta \mathrm{T}$ of $1.61^{\circ} \mathrm{C}$ in phase 3 of decomposition of EFB. When all the chemical bonds of EFB were broken down, $\Delta \mathrm{T}$ endo-up became smaller.

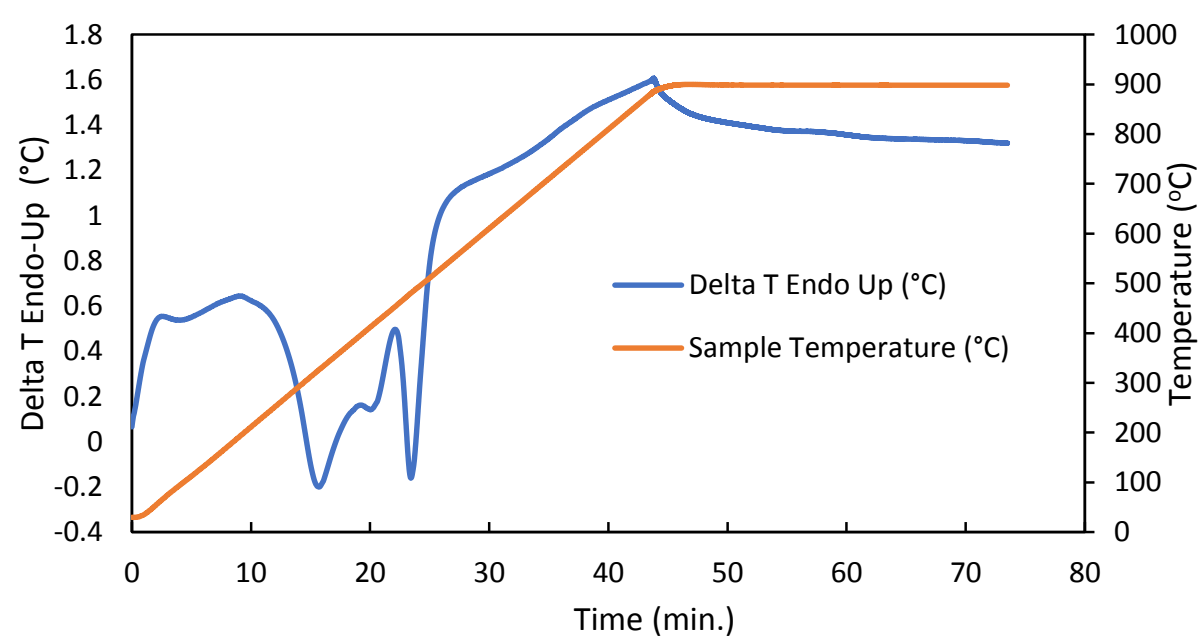

Fig. 2. Time against $\Delta \mathrm{T}$ Endo-up

Fig. 3 shows temperature and time reaction on heat flow endo-up of EFB. In drying and evaporation (phase 1), the heat flow endo-up reached the maximum point of $31.17 \mathrm{~mW}$ at 9.1 minutes. Once the drying and evaporation completed, heat flow endo-up decreased and 
reached minimum value of $15.27 \mathrm{~mW}$ at 15.69 minutes. The devolatilization (phase 2) took place at 22 minutes and the maximum point of heat flow was $28.5 \mathrm{~mW}$. The decomposition in phase three reached the highest points of the heat flow rate of $48.05 \mathrm{~mW}$ at the time of 43.7mintues. In conjunction of temperature against heat flow endo-up, the temperature of the phase 1 was $194.13^{\circ} \mathrm{C}$, whereas phase 2 devolatilization experienced decreasing heat flow endo-up in the temperature ranging from $200^{\circ} \mathrm{C}$ to $326^{\circ} \mathrm{C}$ and there was a slight increment of heat flow (maximum values of $28.51 \mathrm{~mW}$ ) at the temperature of $453.2^{\circ} \mathrm{C}$. Prior to entering phase three, there was a drop of heat to $48.05 \mathrm{~mW}$ at the temperature of $884.85^{\circ} \mathrm{C}$.

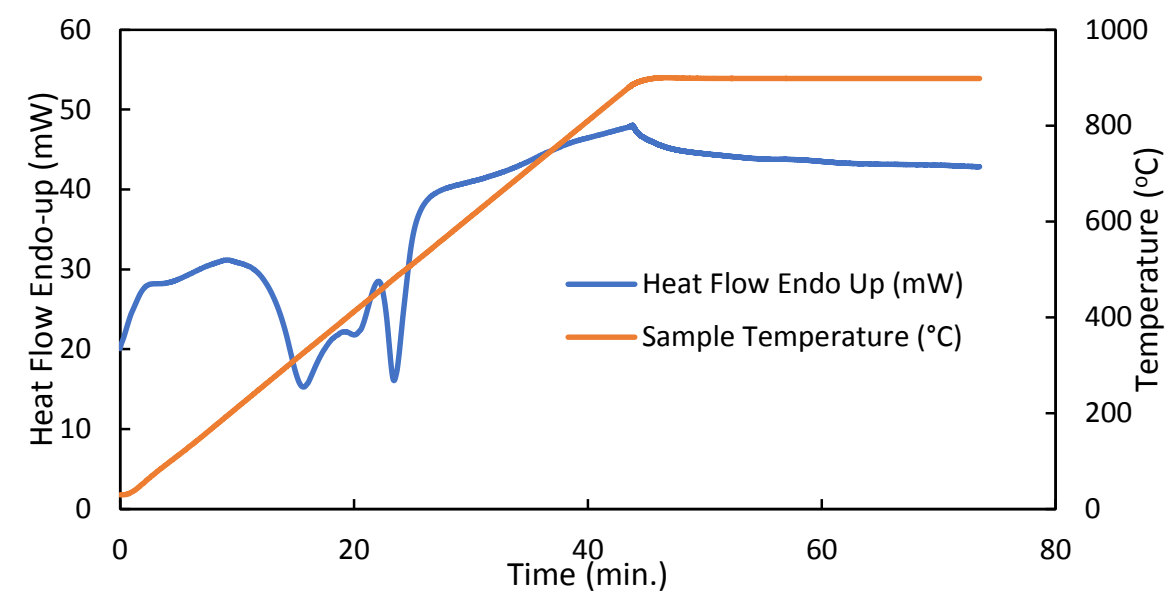

Fig. 3. Time against Heat Flow Endo-up

Fig. 4 shows temperature profile over time. The analysis started at $29.71^{\circ} \mathrm{C}$ (controlled room temperature). As the time increases temperature increases with the rate of $8.5^{\circ} \mathrm{C} / \mathrm{min}$ (point 1 taken at $0.1 \mathrm{~min}$ and $29.69^{\circ} \mathrm{C}$, point 2 at $1.3 \mathrm{~min}, 69.88^{\circ} \mathrm{C}$ ). The temperature reached maximum value of $899.9^{\circ} \mathrm{C}$ at 46.74 minutes, which was then similar until the end of the analysis.

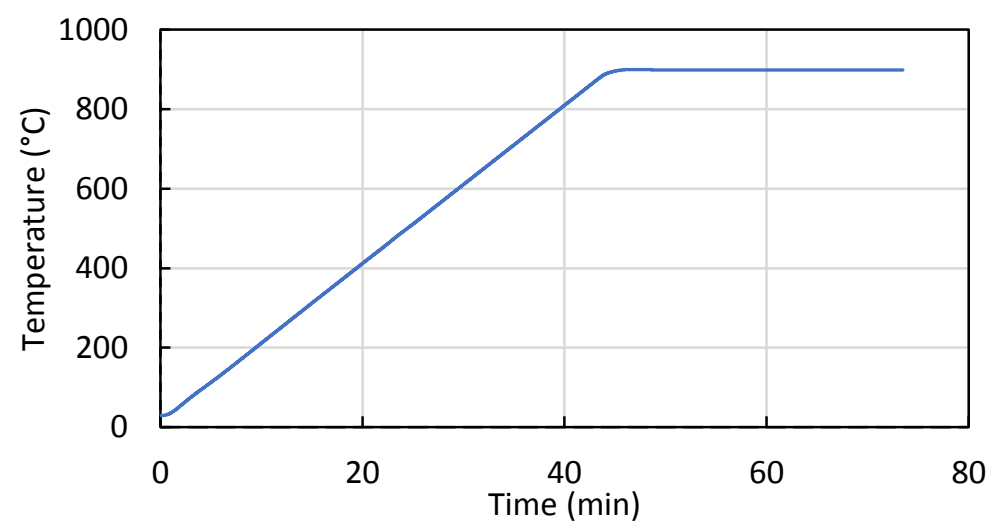

Fig. 4. Temperature against time

\section{Conclusion}


A study on the thermogravimetric analysis of empty fruit bunch (EFB) was carried out to determine weight loss over temperature and time. The analysis showed that the minimum temperature required to break down all the organic chemical component of EFB was at $900^{\circ} \mathrm{C}$ with an approximate period of 46.74 minutes. Through TGA, the reactions of EFB in each phase towards heat flow, $\Delta \mathrm{T}$ endo-up, and time have shown significant changes due to increment of temperature. Analysis of EFB under TGA and DTG at heating rate of $8.5^{\circ} \mathrm{C} / \mathrm{min}$ also showed the maximum weight loss rate of $0.209 \% /{ }^{\circ} \mathrm{Cat}$ the temperature of $313.5^{\circ} \mathrm{C}$ and the derivative weight peak of $-0.1895 \mathrm{mg} /{ }^{\circ} \mathrm{C}$ at $292^{\circ} \mathrm{C}$.

\section{References}

1. J. Benedek, T.-T. Sebestyén, and B. Bartók. Evaluation of renewable energy sources in peripheral areas and renewable energy-based rural development, Renew and Sus Energy Rev, 90, 516-535 (2018).

2. S. Loh. The potential of the Malaysian oil palm biomass as a renewable energy source. Energy Conve and Mang, 141, 285-298 (2017).

3. J. Saldarriaga, R. Aguado, A. Pablos, M. Amutio, M. Olazar, and J. Bilbao. Fast characterization of biomass fuels by thermogravimetric analysis (TGA). Fuel, 140, 744751 (2015).

4. J. Zamzam, W. Kheng, and N. Kamaruddin. Greener energy solutions for a sustainable future: issues and challenges for Malaysia. Ener Policy, 31(11), 1061-1072 (2003).

5. Y. Sudiyani, D. Styarini, E. Triwahyuni, K. Sembiring, Y. Aristiawan, H. Abimanyu, and M. Han. Utilization of Biomass Waste Empty Fruit Bunch Fiber of Palm Oil for Bioethanol Production Using Pilot-Scale Unit. Energy Procedia, 32, 31-38 (2013).

6. R. Khatun, M.I.H. Reza, M. Moniruzzaman, and Z. Yaakob. Sustainable oil palm industry: The possibilities. Renew and Susta Energy Rev, 76, 608-619 (2017).

7. S. Kerdsuwan, K. Laohalidano. Renewable Energy from Palm Oil Empty Fruit Bunch. Ren energy-trends and appli. InTech, (2011).

8. S. Chang. An overview of empty fruit bunch from oil palm as feedstock for bio-oil production. Bio and Bioenergy, 62, 174-181 (2014).

9. S.K. Chembukulam, A.S. Dandge, N.L.K. Rao, K. Seshagiri, R. Vaidyeswaran. Smokeless fuel from carbonized sawdust. Indust \& Eng Chemistry Process Desi and Devel, 20, 714-9 (1981).

10. Z. Zhang, M. Zhu, and D. Zhang. A Thermogravimetric study of the characteristics of pyrolysis of cellulose isolated from selected biomass, Appl Energy, 220, 87-93 (2018).

11. M. Monir, A. Abd Aziz, R. Kristanti, and A. Yousuf. Co-gasification of empty fruit bunch in a downdraft reactor: A pilot scale approach. Bioresource Technology Reports, 1, 39-49 (2018).

12. G. Leal, L. Ramos, D. Barrett, A. Curvelo, and C. Rodella. A thermogravimetric analysis (TGA) method to determine the catalytic conversion of cellulose from carbon-supported hydrogenolysis process. Thermochemical Acta, 616, 9-13 (2015).

13. J. Akhtar, N.S. Amin. A review on operating parameters for optimum liquid oil yield in biomass pyrolysis. Renew and Sustain Energy Reviews, 16(7), 5101-5109 (2012).

14. Y. El may, M. Jeguirim, S. Dorge, G. Trouvé, and R. Said. Study on the thermal behaviour of different date palm residues: characterization and devolatilization kinetics under inert and oxidative atmospheres. Energy 44 (1), 702-709 (2012). 